\title{
Discussion of Digital Teaching For Three-Dimensional Structure
}

\author{
Jimin Qiao \\ Shandong Woman University department of the Arts \\ Jinan China \\ Qiaojimin1217@163.com
}

\begin{abstract}
In the digital era, the teaching mode of basic courses in Colleges and universities of our country tradition has been the "digital" reform, CAI (Computer Assisted Instruction) more and more into the teaching field, gradually making the stereoscopic teaching traditional into the digital. This method can solve is how to help them to establish a three-dimensional modeling based on. Because most of the students thinking in images is fixed on the plane basis, through the teaching process of digital, using virtual reality technology, can quickly let the students have a new understanding of the $3 D$.
\end{abstract}

Keywords- teaching mode; digital; computer aided teaching

\section{THREE-DIMENSIONAL COMPOSITION TEACHING Mode Analysis Of The Status Quo At The PRESENT STAGE}

Three-dimensional structure is the basis of modern art design one, since twentieth Century eighty years into our country, become the common basic course of all art colleges in china. Three-dimensional structure is based on the vision with certain materials, mechanics as the basis, the other elements, in accordance with the principle of the combination method, forming good form. In the field of design many, is a required course for the professional.

Current situation: as a freshman students already have a certain art foundation, and has completed the basic modeling and 2D design before learning the course, have certain professional knowledge and skills, mutual exchanges and cooperation between the students is basically established, the professional teachers are using the form to complete teaching practice course, also is the simple theory knowledge teaching after years of excellent works, comments, on the analysis, the next step is to group discussion for homework, and then homework exhibition. Students only need to complete one to two sets of spatial form of operation in the teacher's subject is good, form requires a simple, single material, without the need of teaching equipment, the direct application of the actual material to complete the creation of students, sometimes due to material and process constraints students scribbled finished, only in forms and ideas on a point it is difficult to understand in-depth thinking, limited student modeling research and space form of the deep. This mode of teaching, to a certain extent, requires students to actively participate in the teaching process, the role of students in the learning process and relative independence.

Situation two: three-dimensional structure of stereo, spatial concepts, most of the more abstract, difficult to understand, imagine, for space do not have a strong sense of students, only is not enough to improve the spatial modeling ability to explain the theoretical knowledge and years of work. A simple sketch can only be viewed from one angle, only through a lot of practice to be improved, which requires students to use different materials, different forms of physical exercise, which is time-consuming and consumables, at the end of the course, students in the classroom will be the accumulation of a large number of abandoned unqualified works, although the students improve in practice ability to students, but also bring economic waste.

Situation three: teachers in teaching is more of the students, guide the heuristic teaching, one-on-one instruction mode. For a shapeless work, teachers will be a guide, give guidance from each link of the whole shape, space, form, color, sometimes one works to repeat back and forth several times in order to improve the adjustment time, sometimes one works for 10 minutes, there are 30 students in a class, a class 45 minutes, so sometimes a class tutors not a few students, some students start perfunctory accomplished something, the class teacher's heavy workload, the learning interest of the students can not improve.

In view of the existing problems in the teaching of the above situation, combined with the author's teaching experience of many years, there have been many malpractices in the traditional teaching mode, to improve the teaching quality and effect in the course of teaching, we must keep pace with the times. Understand the root, at present in the teaching course in most universities, has a large number of applications of digital teaching mode, and combined with traditional teaching methods, teaching process,

\section{APPLICATION OF DigitAL TECHNOLOGY IN THE TEACHING OF}

With the popularization of digital art, traditional universities teaching mode has been "change and development of digital", the most common phenomenon is, digital teaching methods have been widely used in the teaching process of teachers, its application is not only in the simple application of multimedia courseware in teaching, but in the whole process of classroom teaching, make full use of digital network environment, rich teaching resources and the teaching video, audio, text and other digital means, the completion of teaching.

In the teaching process, the boring text for the concept of no contact with knowledge of students is undoubtedly the 
cramming teaching effect, a class down the mind is full of concept, based on this phenomenon, the author investigated some freshman, $90 \%$ of the students in high school have come into contact with the network, and also understanding of some related software, based on such phenomenon, can be combined with digital image, in theory teaching process picture, and related software combined with the theory of teaching. For example, in explaining the composition structure layout, related tools can use 3Dmax software to complete the segmentation. Using visual presentation form of the originally dull as ditch water text fresh activation. From the students' interest in learning it, digital teaching lively make boring learning content is easier to understand, in the classroom but also allows students to participate in, complete with interactive teaching form. In the digital teaching mode, can observe the change of form and space division method, the application can also be through the studying of this course to learn more about the software.

Students in the process of practice, can be applied to CAI (Computer Assisted Instruction), students can according to their proposition work, using the Sketchup (master plan), Rhinoceros, AutoCAD, 3DMAX and other related software on the subject after practice. First of all, teachers can course in every part of layout related content of practice, such as the constitution of rhythm and rhyme arrangement, line performance, surface layer column combination relations were each given exercises, selected topic, the use of hand on the data or information to the teacher according to the idea of data analysis and modification, design completed a preliminary draft by the teachers review. Secondly, the specific design students can use the software of the electronic manuscript completed the draft design, during the design process, the students can not to consider more design materials, with what tools, color, but simply to consider the shape of space, open the students thinking, so that students can more easily handle form complex relationships in practice, to enable students to understand the $3 \mathrm{D}$ surface to penetrate into the interior, let the students find the pleasure in learning, just play the game space combination. In this way, save a lot of time and materials, the study focuses on the training of thinking and sculpture.

Application of digital technology and computer aided design software, let teacher liberated in the classroom, heavy teaching work and traditional teaching mode for teachers to a world to be tired out, without much effort to prepare. Due to the digital intervention, teachers can each team uniform selection scheme, let each group member to make themselves satisfied with the program, with the form of slide introduced design of each scheme and the use of space combination forms. Students can learn from each other, mutual comment, interactive forms after the end of the selected scheme, teachers, students can combine with the related materials to complete the physical production design. This form of teaching to students to avoid wasting time cutting material constantly, constantly modify scheme, save the material purchasing, processing and other trouble. This process not only embodies the interaction between teaching and learning, let students self-conscious show, accept the knowledge.

\section{Digital Teaching PROBlems}

Application of digitalization, compared with the traditional teaching method course, digital technology is more intuitive, image, a large amount of information, make our teaching quality has been greatly improved, the teaching effect is obviously improved, which shows the digital teaching methods is superior to traditional classroom teaching more significant. But in front of the advantage is still a problem.

Now China's education industry vigorously promote the multimedia teaching, but the current situation, there are many teachers did not fully combined with the advantages of digital era of cyber source and digital media platform, it is difficult to make courseware application software, scribbled some multimedia courseware making, cannot show the teaching focus, difficulties. Multimedia courseware making some teachers focus on pictures, sound effects, the accuracy of ignoring the teaching content, the courseware be flashy without substance. Teachers should according to the characteristics of the course itself to grasp the teaching content of digital level, pay attention to the content and methods of balance, by means of technology related to the reasonable expression of the lectures, avoid the effect brought about by the inhibition of excessive digital teaching effect.

Teachers should understand the digital technology level of students in the teaching process, many teachers tend to ignore the importance of understanding the students, according to the current understanding of college students to accept ability and application of network and digital media technology is strong, but because the freshman just came, now also available without computer, you must provide room for students of professional teachers, but for the related software or some strange, first of all is to ask the teachers must be familiar with the related software, but also the teacher introduced the related software, under the guidance of teachers, students should be designed to combine simple commands, let the students to express their ideas to complete it, related software used in the course, the students can not that is the software course, wasting time in the process of scheme design.

Three-dimensional software design work is solid, but the virtual space, we can see the structure of the work from different angles, but students not in real space of structure and texture work, also must use the relevant materials in order to achieve the purpose of physical curriculum requirements, which requires the teachers to guide, or to attention to the classroom teaching effect and teaching objective.

\section{CONCLUSIONS}

Introducing the teaching mode of digital technology, three-dimensional composition can improve the students based on the traditional mode of education is weak, timeconsuming, and the expression is not detailed enough, to a large extent, but the application of teaching mode of digital technology can not be too dependent on, because no matter how sophisticated digital technology used in art design, all 
basic skills of art designers need to own, so we in the use of modern teaching methods at the same time, the traditional techniques and technologies can not be discarded. In addition, the use of digital technology must be combined with practice, so that students can get exercise at the same time in the operation ability, give full play to their own creative ability and innovation ability, go further on their art design road.

\section{REFERENCES}

[1] LiangMa, On China's colleges and universities in the digital age "digital" teaching mode, Computer knowledge and technology, 2011.9, pp. 2210-2211,In Chinese

[2] ShuWu, ChanghongJing, New ideas of teaching reform of modern three-dimensional constitution, Value engineering, 2010.2, pp. 165166, In Chinese

[3] RongWang, Thoughts on improving teaching quality, Threedimensional composition and Wenhui, 2009. pp. 846,In Chinese 